* Mestrando do Programa de PósGraduação da Universidade de Santa Cruz do Sul - UNISC, da linha de pesquisa de Políticas Públicas de Inclusão Social. Integrante do Grupo de Pesquisa "Sociedade de riscos e democracia radical: a formatação de políticas públicas a partir de decisões judiciais", coordenado pelo Professor Pós-doutor Rogério Gesta Leal. PósGraduado em Direito Ambiental pela Uniasselvi. Advogado.E-mail: flaviobarbozadecastro@gmail. com

**Desembargador do Tribunal de Justiça do Estado do Rio Grande do Sul, Doutor em Direito. Prof. Titular da UNISC. Professor da FMP. Professor Visitante da Università Túlio Ascarelli - Roma Trè, Universidad de La Coruña Espanha, e Universidad de Buenos Aires. Professor da Escola Nacional de Formação e Aperfeiçoamento da Magistratura - ENFAM. Membro da Rede de Direitos FundamentaisREDIR, do Conselho Nacional de Justiça-CNJ, Brasília. Coordenador Científico do Núcleo de Pesquisa Judiciária, da Escola Nacional de Formação e Aperfeiçoamento da Magistratura - ENFÁM, Brasília. Membro do Conselho Científico do Observatório da Justiça Brasileira. Coordenador da Rede de Observatórios do Direito à Verdade, Memória e Justiça nas Universidades brasileiras - Secretaria de Direitos Humanos da Presidência da República.E-mail: rleal@unisc.br

\section{AMICUS CURIAE: UM ALIADO NA DEFESA E PROTEÇÃO AO MEIO AMBIENTE}

AMICUS CURIAE: AN ALLY IN DEFENSE AND ENVIRONMENTAL PROTECTION

\section{Flavio Barboza Castro* Rogério Gesta Leal**}

Como citar: CASTRO, Flavio Barboza; LEAL, Rogério Gesta. Amicus Curiae: um aliado na defesa e proteção ao meio ambiente. Revista do Direito Público, Londrina, v. 16, n. 1, p. 119-132, abr. 2021. DOI: 10.5433/24157-108104-1.2021v16n1p. 119. ISSN: $1980-511 \mathrm{X}$

Resumo: Devido à necessidade e urgência de defesa e proteção ao meio ambiente, direito garantido pela ordem constitucional, instrumentos que possibilitam o controle e a participação social em matéria ambiental, recebem apreço. Nessa perspectiva, aborda-se a importância da participação social na garantia do direito fundamental ao meio ambiente, para introduzir o estudo do instituto do amicus curiae, que vem contribuir de forma plena e eficaz nesse objetivo. Sendo esse o quadro, o presente trabalho aponta a seguinte interrogação: o instituto do amicus curiae, que proporciona a participação social nos processos judiciais, trata-se de um instrumento que possibilita a defesa e proteção ao meio ambiente? Cumpre considerar que, para responder essa problemática, utilizar-se-á o método dedutivo e a técnica de pesquisa bibliográfica e jurisprudencial. Concluise que o amicus curiae configura-se em um mecanismo de democratização e pluralização do processo, fazendo com que as decisões que envolvam as questões ambientais fiquem mais alinhadas às demandas sociais, permitindo a participação social e possibilitando a defesa e proteção ambiental.

Palavras-chave: Amicus curiae. Direitos fundamentais. Meio ambiente. Participação social.

Abstract: Due to the need and urgency of defense and protection of the environment, a right guaranteed by the constitutional order, instruments that enable control and social participation in environmental matters, receive appreciation. In this perspective, this paper approaches the importance of social participation in the guarantee of the fundamental right to the environment, in order to introduce the study of the amicus curiae institute, which contributes fully and effectively to this objective. This being the case, this paper poses the following question: is the 
amicus curiae institute, which provides for social participation in judicial proceedings, an instrument that enables the defense and protection of the environment? The deductive method will be used to answer this question, as well as bibliographical and jurisprudential research. The conclusion is that the amicus curiae is configured as a mechanism of democratization and pluralization of the process, making decisions involving environmental issues more aligned with social demands, allowing social participation and enabling the defense and protection of the environment.

Keywords: Amicus curiae. Environment. Fundamental rights. Social Participation. 


\section{INTRODUÇÃO}

Tratados e Pactos Internacionais, desde o século XX, juntamente com a Constituição brasileira de 1988, instituíram uma nova era política, institucional e jurídica no país, fundada nos direitos humanos e fundamentais, erigindo como um deles o meio ambiente sustentável, urbano ou rural, para as presentes e futuras gerações. O direito ao meio ambiente é visto e classificado como direito de terceira geração ou dimensão, por abranger uma proteção coletiva de organização social, possuindo, assim, a chamada natureza difusa. Possui assento no artigo 225 da Constituição Federal, onde não há apenas um direito consagrado, mas um dever de proteção estatal de conservação e preservação ambiental.

Presente esse contexto, o artigo pretende abordar a importância da participação social para a proteção e garantia do direito fundamental ao meio ambiente sustentável, introduzindose, dessa forma, o instituto do amicus curiae, como instrumento de participação social para a proteção a esse direito fundamental, o que se demonstra por meio da jurisprudência pátria. Com esse foco, a problemática consiste: o instituto do amicus curiae, que proporciona a participação social nos processos judiciais, trata-se de um instrumento que possibilita a defesa e proteção ao meio ambiente? Para dar conta dessa tarefa, utiliza-se o método dedutivo, partindo do estudo da importância da participação social na defesa e da proteção ao meio ambiente, para, em seguida, abordar o instituto do amicus curiae e responder a problemática do estudo. Como técnica de pesquisa, tem-se a bibliográfica e jurisprudencial.

Nesse olhar, o artigo possui como objetivos específicos tecer algumas considerações referentes à importância da participação social na defesa, proteção e preservação do meio ambiente.

Serão abordados alguns instrumentos no âmbito dos três Poderes que permitem essa participação social, para, em seguida, conceituar e caracterizar o instituto do amicus curiae, notadamente como mecanismo que propicia a atuação social para a proteção ambiental.

O trabalho, dessa maneira, encontra justificativa tanto por envolver pressupostos sobre a importância da participação social para a defesa, prevenção e proteção ao meio ambiente, como por destacar alguns instrumentos que permitem a proteção ambiental, incluindo-se, aqui, a figura do amicus curiae, que se configura em um grande mecanismo de democratização e pluralização do processo.

Impõem-se destacar, ainda, que a proteção dos direitos fundamentais se dá, cada vez mais, no âmbito da jurisdição, razão pela qual se faz importante e necessário o desenvolvimento de instrumentos que viabilizam a participação social, como é a figura do amicus curiae.

\section{A IMPORTÂNCIA DA PARTICIPAÇÃO SOCIAL NA DEFESA E PROTEÇÃO AO DIREITO AMBIENTAL}

O sistema constitucional brasileiro é emoldurado pela possibilidade de reconhecimento autônomo do direito subjetivo ao meio ambiente, em relação aos outros valores constitucionais, 
diferentemente do que acontecia nas Constituições brasileiras anteriores. É direito dos cidadãos brasileiros questionar qualquer ato que seja praticado pelo particular, bem como pelo poder público, que possa causar dano ao meio ambiente (GAIO, 2015). Isso é corroborado por Leal (2013), o qual compreende que a política ambiental não pode carecer apenas da atuação do poder público, mas de ações solidariamente responsáveis que envolvam tanto o Estado quando a coletividade.

Esse entendimento reflete-se, também, no magistério de Leal e Maas (2014, p. 45), no qual a participação dos cidadãos é necessária, de forma que a sociedade trace seus próprios caminhos. Vê-se, portanto, um caminhar a uma democracia pluralista, em que os próprios cidadãos são legitimados e aptos a participarem do processo que envolva a discussão de um direito, no caso, do direito fundamental ao meio ambiente ecologicamente equilibrado.

Com a participação ativa, ou, ao menos, com a possibilidade dela, há uma probabilidade de assegurar e fiscalizar o direito a ser preservado, no caso, ao meio ambiente saudável, sendo algo inerente à democracia, preservando os interesses de toda a sociedade, no caso, às presentes e futuras gerações. Isto está ligado ao exercer o direito de cidadania, que é a base do Estado Democrático de Direito, proclamado na Carta Magna pátria.

O reconhecimento do direito ao meio ambiente exige dos diferentes agentes de decisão (legisladores, juízes e administradores públicos) posicionamentos quando os interesses ambientais estiverem em conflito com valores constitucionais e isso envolver efeitos ambientais significativos, como é o caso de conflitos entre o direito de propriedade e os avanços tecnológicos e o meio ambiente.

A partir de uma perspectiva material, o constituinte determinou à coletividade o direito subjetivo de viver em um ambiente ecologicamente equilibrado, devendo ser considerado “essencial à sadia qualidade de vida", conforme dispõe o caput do artigo 225 da Constituição Federal (BRASIL, 1988). Ao realizar essa consignação, o legislador incluiu a proteção ao meio ambiente entre os valores fundamentais da República, motivo pelo qual qualquer alteração ou supressão no texto do referido artigo configura flagrante violação aos direitos fundamentais.

Ninguém desconhece que, em razão da estreita relação entre o direito ao meio ambiente e o direito à vida, o primeiro não pode ser alvo de emenda constitucional, estando, consequentemente, inserido no rol de conteúdos previstos no artigo 60, $\S 4^{\circ}$, da Carta Magna, de tal modo que possui caráter de cláusula pétrea (BRASIL, 1988).

Outra não poderia ser a interpretação constitucional dada ao direito ao ambiente, em vista da consagração da sua jusfundamentalidade. A consolidação constitucional da proteção ambiental como cláusula pétrea corresponde à decisão essencial da Lei Fundamental brasileira, em razão da sua importância do desfrute de uma vida com qualidade ambiental à proteção e equilíbrio de todo o sistema de valores e direitos constitucionais, e especialmente à dignidade humana (SARLET; FENSTERSEIFER, 2017, p. 84).

O entendimento constitucional de ser o direito ao meio ambiente uma cláusula pétrea está de acordo com a vedação constitucional do retrocesso, ou seja, de um direito social já conquistado 
e devidamente posto como um preceito fundamental, principalmente no que tange à dignidade da pessoa humana e a questões ambientais. Apreciando esta questão em face do texto constitucional de 1988, em preciso magistério Leite (2003, p. 198) assevera que: “[...] o direito fundamental ao meio ambiente não admite retrocesso ecológico, pois está inserido como norma e garantia fundamental de todos, tendo aplicabilidade imediata."

Tem-se por imprescindível a composição de alternativas para a relação entre homem e natureza, para buscar um cenário mais amplo e claro para sopesar a ambiência a envergadura e conformação dos fatos, pois, diante do vigente sistema econômico, marcadamente capitalista, o futuro de ambos é incerto. A humanidade precisa repensar a forma como consome, pois, de acordo com Boff (2015, p. 143), “[...] esse tipo de sociedade vigente é, sem dúvida, profundamente antiecológico." O que constitui um dos fatores explicativos da atual degradação do Sistema Terra.

Outro aspecto que implica nessa degradação é o atual sistema altamente capitalista, valendo-se dos bens naturais para produzir retornos financeiros sem priorizar as consequências desastrosas que poderá trazer ao sistema ecológico que rege a vida humana.

Para equilibrar o alcance de tal afirmação, Leite (2003, p. 22) assinala que, inobstante a ideologia, a sociedade tem dificuldade de lidar para com a crise ambiental, "[...] considerando que o capitalismo industrialista, no primeiro caso e o coletivismo industrialista, no segundo, pôs em prática um modelo industrial agressivo aos valores ambientais da comunidade."

Disso resulta a imprescindibilidade de inserção do direito ao meio ambiente no rol de direitos fundamentais, cuja à cláusula, foi corretamente e amplamente considerada pelo legislador constituinte de 1988, que fez previsão do meio ambiente ecologicamente equilibrado, mas também de um conjunto de regramentos e deveres que visam garantir, organizar e servir como ferramenta de proteção ao meio ambiente, permanentemente em colaboração com a promoção e proteção de outros direitos, como à vida e à dignidade humana.

Cabe destacar, tendo presente o contexto em questão, que assume papel de fundamental importância o princípio da participação social ou comunitária ou o princípio democrático, que reforça a importância da participação social em matéria ambiental, já consolidada de forma unânime na legislação e na doutrina, sendo que, conforme observa Trennepohl (2007, p. 38), “[...] a evolução da positivação da proteção ao meio ambiente tornou-se um imperativo fundamental de sobrevivência e solidariedade."

Inquestionável, desse modo, a análise do princípio da participação comunitária, princípio esse tido como fundamental à medida do envolvimento do Estado e do cidadão no equacionamento e na implementação da política ambiental. No Brasil, este princípio está contemplado no artigo 225, caput, da Constituição Federal, ali estando prescrito ao Poder Público e à coletividade o dever de defender e preservar o meio ambiente para as presentes e futuras gerações (BRASIL, 1988).

Não custa relembrar, neste ponto, considerada a essencialidade do princípio constitucional, precedentemente ressaltado, que o sufrágio universal passou a não mais satisfazer totalmente o eleitor que almeja uma maior participação no conjunto de decisões, o que tem levado os cidadãos a pleitear uma ação mais próxima dos órgãos de controle no que diz respeito ao meio ambiente. Nesse 
sentido, a participação dos cidadãos e de Organizações não Governamentais (ONGs) não pode ser compreendida de forma a obstaculizar os integrantes da Administração Pública, tampouco, ela não é substitutiva da atuação do Poder Público, mas sim, com o importante propósito de apontar caminhos e soluções no âmbito das questões de cunho ambiental (MACHADO, 2016).

É importante ter presente, que o direito ambiental é um direito que tem suas origens nos movimentos reivindicatórios dos cidadãos e, como tal, é essencialmente democrático. Os direitos à informação e participação no meio ambiente, materializam-se por meio do princípio democrático que assegura aos cidadãos o direito pleno de participar na elaboração das políticas públicas ambientais (AMADO, 2017).

Não constitui demasia relembrar, que o princípio democrático ou da participação está fundamentado essencialmente no princípio décimo da Declaração do Rio de 1992. Este princípio está calcado em dois pontos importantes: a) informação; e b) conscientização ambiental. Se o cidadão não tiver consciência ambiental, a informação não lhe servirá para nada (SIRVINSKAS, 2018, p. 145). Reza tal princípio:

A melhor maneira de tratar questões ambientais é assegurar a participação no nível apropriado, de todos os cidadãos interessados. No nível nacional, cada indivíduo deve ter acesso adequado a informações relativas ao meio ambiente de que disponham as autoridades públicas, inclusive informações sobre materiais e atividades perigosas em suas comunidades, bem como a oportunidade de participar em processos de tomadas de decisões. Os Estados devem facilitar e estimular à conscientização e a participação pública, colocando a informação a disposição de todos. Deve ser propiciado acesso efetivo e mecanismos judiciais e administrativos, inclusive no que diz respeito à compensação e repartição de danos (RIO DE JANEIRO, 1992).

É por tal razão que Carvalho (2008, p. 20), acentua que o direito ambiental vem impor e demandar ao Estado uma alteração na conformação de seu exercício democrático, no sentido de haver certa relativização da democracia representativa em face de formas de participação direta dos cidadãos. Ou seja, abandona-se a concepção simplista de que participação política da sociedade se restringe ao âmbito de uma participação política representativa, estendendo-se ela a outras dimensões, a existência de uma via de participação direta dos cidadãos em defesa da questão ambiental.

Daí se afirmar que Estado e sociedade devem andar juntos para dar conta dos problemas ambientais aos quais se vive, pois, não há como se adotar uma visão individualista sobre a proteção ambiental, isto é, sem solidariedade e desprovida de responsabilidades difusas globais. Por isso, somente com a mudança para a responsabilização solidária e participativa dos Estados e dos cidadãos, em uma união entre estes dois polos, com firmes ideais de preservação ecológica, é que se tornará possível encontrar solução para a crise ambiental, conforme traz Leite (2008).

Eis a observação constante do magistério de Leite (2003), em que a participação social se torna importante pela transparência que confere ao processo e pela legitimidade que traz à decisão ambiental, contribuindo, desse modo, para uma conscientização ambiental. Esta transparência 
no processo implicará, ainda, em uma decisão ambiental potencialmente mais próxima de um consenso, com vistas à aceitação da coletividade e para a produção de seus efeitos de forma mais específica.

Cabe destacar, por extremamente relevante, a criação e o desenvolvimento de instrumentos aptos de participação ativa da sociedade em matéria ambiental se fazem primordial para resultados positivos, assim como uma atuação democrática e consciente dos indivíduos. Leite (2008, p. 161) ainda afirma que “[...] todo problema de política ambiental só poderá ser resolvido quando reconhecida a unidade entre cidadãos, Estado e meio ambiente, e garantidos os instrumentos de ação conjunta."

Destaca-se, desde logo, que a efetivação dos direitos fundamentais, carece da participação cada vez mais ativa do cidadão, em vista de que as questões ambientais representam, na atualidade, um problema de gravidade extrema que ataca toda a sociedade, comunidade brasileira, e que deverá ser resolvido por ações múltiplas, como, por exemplo, ações legislativas, sociais/de grupos; ações políticas; e ações jurídicas (BIANCHI; FERREIRA, 2008).

Mencionados alguns pressupostos sobre a importância da participação social no que concerne ao meio ambiente, prossegue-se incorporando alguns instrumentos capazes de permitir que esta participação ocorra para o fim de proteção ambiental. De início, apresentam-se instrumentos constantes na Constituição Federal, sendo eles: o plebiscito, o referendo e a iniciativa popular. Esses instrumentos são compreendidos como mecanismos de participação no âmbito do Poder Legislativo, em que poderá ocorrer a participação social também na forma de cobrança ou de incentivo a medidas de representantes eleitos, bem como pela participação nas Comissões do Meio Ambiente, na Câmara dos Deputados e no Senado Federal, e nos legislativos estaduais e municipais, comissões estas que servem de fórum para discussões de interesse da sociedade.

Ainda, aqui, encaixa-se, no sentido de participação na criação do direito ambiental, segundo Leite (2008), a atuação de representantes da sociedade civil em órgãos colegiados, dotados de poderes normativos, como é o Conselho Nacional do Meio Ambiente (Conama) (artigo $6^{\circ}$, inciso II, da Lei n. 6.938/81, com redação dada pela Lei n. 7.804 e pela Lei n. 8.028/90).

Sendo esse o contexto, examina-se, preliminarmente, a questão do Poder Executivo, que na análise de Furriela (2002) destaca como espaço que propicia a participação social, os Conselhos de Meio Ambiente nos níveis federal, estaduais e municipais. Nessa acepção, Leite (2008) coloca, no sentido de via de participação na formulação e na execução de políticas ambientais, em que os cidadãos podem atuar diretamente na tutela ambiental, participando das políticas, por meio da ação dos representantes na execução de políticas públicas e por ocasião da discussão de Estudo Prévio de Impacto Ambiental (EIA/Rima) em audiências públicas.

Já no âmbito do Poder Judiciário, há diferentes tipos de ações que podem ser utilizadas para a defesa do meio ambiente, destacando-se, pontualmente, a Ação Popular e a Ação Civil Pública; já em nível de controle de constitucionalidade, têm-se a Ação de Inconstitucionalidade por Omissão, a Ação Direta de Inconstitucionalidade, a Arguição de Descumprimento de Preceito Fundamental, bem como os remédios constitucionais do Mandado de Segurança e o Mandado de 
Injunção, entre outros.

Dessa maneira, após cingir pressupostos referentes à participação social no meio ambiente e alguns instrumentos e espaços que propiciam essa participação, passa-se a caracterizar a figura do amicus curiae e trazê-la como instrumento de participação social para a proteção e defesa ambiental.

\section{A INTERVENÇÃO DO AMICUS CURIAE COMO INSTRUMENTO NA DEFESA E PROTEÇÃO AO MEIO AMBIENTE}

O amicus curiae, o "amigo da corte" ou o "amigo do juiz", possui seus antecedentes mais remotos no direito romano, tendo a sua ascendência ocorrida no direito inglês medieval e, posteriormente, teria o instituto amadurecido com o seu desembarque nas "13 colônias" (DEL PRÁ, 2007). Todavia, não é pacífica na doutrina a origem do instituto, o certo que a sua evolução ocorreu nos Estados Unidos da América, recebendo ali, os caracteres próximos do mecanismo na atualidade:

Embora, para alguns, o instituto tenha surgido já no direito romano, foi no direito inglês medieval que o amicus curiae adquiriu as bases de suas características modernas, vindo a institucionalizar-se, já em pleno início do Século XX, nos Estados Unidos, onde evoluiu e alcançou grande relevo, surgindo como instrumento de manifestação daqueles que eram alheios ao caso (não eram, portanto, partes do processo sob análise), mas que elaboravam e apresentavam ao julgador um parecer jurídico composto por precedentes cabíveis, porém não examinados ou invocados pelas partes, além de questões de direito úteis e relevantes para a solução da lide (LEAL; MAAS, 2014, p. 55-56).

Impõem-se registrar, que no Brasil a intervenção do amicus curiae encontra seu fundamento na necessidade de que informações estranhas ao processo se tornassem acessíveis ao magistrado (SANTANA, 2019). Aqui, o instituto só obteve notoriedade com a sua inserção na Lei 9.868, de 10 de novembro de 1999, que disciplina Ação Direta de Inconstitucionalidade e Ação Declaratória de Constitucionalidade (BRASIL, 1999a).

No entanto, possui mais de quatro décadas de existência em solo brasileiro, tendo sido, inicialmente, introduzido em 16 de dezembro de 1978, por meio da Lei 6.616, que trouxe alterações à Lei 6.385, de 7 de dezembro de 1976, que regulamenta o mercado de valores mobiliários e criou a Comissão de Valores Mobiliários (CVM), porém não aparece com essa terminologia (AGUIAR, 2005).

Ainda, é importante destacar que a primeira vez que a figura do amicus curiae apareceu no direito pátrio com essa denominação foi na Resolução n. 390, de 17 de setembro de 2004, do Conselho da Justiça Federal, em seu artigo 23, parágrafo primeiro, que se refere, expressamente, a figura por ocasião do incidente de que trata o artigo $14, \S 7^{\circ}$, da Lei 10.259 , de 12 de julho de 2001, que dispõe sobre as instituições dos Juizados Especiais Cíveis e Criminais no âmbito da Justiça 
Federal (LEAL; MAAS, 2014).

Impende destacar, neste ponto, no magistério de Souza (2007) que o instituto possui como característica própria o fato de ser amigo da Corte e não das partes, por se inserir no processo como terceiro, que não os litigantes iniciais da causa, movido por um interesse maior que o daqueles, representando a própria sociedade no debate. Desse modo, o instituto não intervém em uma demanda para beneficiar uma ou outra parte, mas sim, para trazer informações relevantes para o melhor entendimento da matéria e deslinde da demanda, vindo a pluralizar e democratizar o processo e, principalmente, permitir que a sociedade participe das decisões que venham afetar, prejudicar e/ou beneficiar um de seus direitos.

Todavia, esse não é o posicionamento único referente ao instituto, sendo compreendido, também, como um terceiro parcial, nas feições de um "amigo da parte":

Pode-se conceituar o amicus curiae como um terceiro que intervém na lide de forma (des)interessada, alguém que, apesar não estar litigando, possui interesse na matéria sub judice e que pretende, com a sua intervenção, beneficiar os interesses de uma das partes na causa, ou uma determinada posição - visto o caráter objetivo das ações do controle concentrado de constitucionalidade -, abandonando, em certa medida, a pretensa neutralidade original que the é atribuída em seu sentido original (LEAL; MAAS, 2014, p. 71).

Apesar de distintos entendimentos sobre o instituto, Carvalho (2008) relata que a figura do amicus curiae, da forma em que é vista no ordenamento jurídico brasileiro, consiste em uma figura ímpar no campo processual, sendo que se caracteriza como um especial elemento de colaboração ao exercício da jurisdição.

Na realidade, o instituto é de grande relevância, pois amplia o debate do objeto da causa e, de tal modo, proporciona ao Estado julgador uma visão mais clara da questão a ser decidida, transcendendo os aspectos fáticos e jurídicos, dando uma maior dimensão das consequências do julgamento, sendo que esses elementos informativos poderiam passar despercebidos à análise da Corte.

Cabe reconhecer, em suma, dessa maneira, que essa é a função histórica do amicus curiae, ou melhor, chamar a atenção da Corte para fatos ou circunstâncias que não poderiam ser notados sem a intervenção do "amigo da corte". Assim, o amicus curiae exibe um documento ou memorial, como também, pode realizar sustentação oral, interpor recurso quando da sua inadmissibilidade ou participar das audiências públicas (neste caso, quando convocado, como foi o caso da Arguição de Descumprimento de Preceito Fundamental n. 101, abaixo observada) ${ }^{1}$ (BRASIL, 2009), para informar o órgão julgador sobre determinado assunto polêmico, de relevante interesse social, que é objeto de julgamento, dando suporte fático e jurídico à questão sub judice, enfatizando os efeitos dessa questão na sociedade, na economia, na indústria, no meio ambiente, ou em quaisquer outras áreas em que essa discussão possa causar influências (SANTOS, 2005).

Apuradas essas questões referentes ao amicus curiae, não se pode desconhecer que ele está atrelado a algo maior, sendo utilizado para o valor máximo inerente à pessoa humana,

\footnotetext{
1 Atualmente, o amicus curiae possui as seguintes prerrogativas, desde que representado por advogado: manifestar-se por escrito, realizar sustentação oral e recorrer da decisão de sua inadmissibilidade (e não das decisões da causa em que intervém). Também, poderá participar, quando assim convocado, de audiências públicas. Esses são os poderes

do instituto previsto no controle concentrado de constitucionalidade e no Código de Processo Civil (LEAL; MAAS, 2014).
} 
conforme expõe Souza (2007, p. 239):

A proteção da dignidade humana, da igualdade, do direito ao trabalho, do direito à terra, do direito a um meio ambiente salubre, do combate à discriminação racial e ao racismo, do direito à liberdade de religião e de culto, de liberdade de imprensa, do direito à vida, da garantia de prerrogativas funcionais e institucionais, entre outros.

Cumpre ainda ressaltar que a intervenção do amicus curiae no processo do controle concentrado de constitucionalidade vem com o fim de pluralizar o debate constitucional e propiciar uma maior abertura na interpretação constitucional (alcançando tais efeitos nos processos ordinários, pela sua previsão no novo Código de Processo Civil, como se mencionará). Tal como assinalado, observa-se que, por meio do amicus curiae, a Corte Constitucional pode escutar a sociedade, de modo a permitir que essa interfira na formação da decisão final, passando de simples destinatária das normas constitucionais à condição de sua intérprete (LEAL; MAAS, 2014).

É importante sempre destacar que a prerrogativa concernente ao amicus curiae se mostra como um instrumento que, além de trazer informações relevantes ao processo, democratizando-o e pluralizando-o, configura-se como um grande mecanismo que vem permitir a participação social para a proteção do meio ambiente, pois, oportuniza que a sociedade, agentes sociais, órgãos e entidades de controle possam debater assuntos que venham prejudicar o direito a um meio ambiente ecologicamente equilibrado.

Desse modo, com essa finalidade e de forma explicativa, tem-se a presença da figura na Ação Direita de Inconstitucionalidade n. 3378/DF, em que se debateu a constitucionalidade do artigo 36 e seus $\S \S 1^{\circ}, 2^{\circ}$ e $3^{\circ}$ da Lei 9.985 , de 18 de julho de 2000 , no que se ocupa a compensação devida pela implantação de empreendimentos de significativo impacto ambiental (BRASIL, 2008). Também, cumpre referir que houve a manifestação do instituto na Medida Cautelar na Ação Direta de Inconstitucionalidade n. 3540/DF, em que se discutia a constitucionalidade do artigo $4^{\circ}$ do Código Florestal, alterado pela Medida Provisória n. 2.166-67, que estabeleceu mecanismos que permitiam um controle, pelo Estado, das atividades desenvolvidas no âmbito das áreas de preservação permanente com o fim de impedir ações predatórias e lesivas ao patrimônio ambiental. Menciona-se que na Ação Direta de Inconstitucionalidade são os artigos $7^{\circ}, \S 2^{\circ}$, e $9^{\circ}, \S 1^{\circ}$ da Lei 9.868/992 , que permitem a intervenção do instituto (BRASIL, 2005).

Oportuno mencionar, ainda, em face de absoluta pertinência, a intervenção do amicus curiae na Arguição de Descumprimento de Preceito Fundamental n. 101/DF, sobre a importação de pneus usados, que ofendem os artigos 196 e 225 da Constituição Federal, que dizem respeito, respectivamente, ao direito à saúde e ao meio ambiente (BRASIL, 2009). Nesse caso, também, foi realizada pelo Supremo Tribunal Federal audiência pública, em que foram ouvidos vários amici curiae. Aqui, a intercessão da figura é prevista no artigo $6^{\circ}, \S 1^{\circ}$ e $\S 2^{\circ}$, da Lei 9.882 , de 3 de

2 "Art. 7o Não se admitirá intervenção de terceiros no processo de ação direta de inconstitucionalidade.

$\S 1^{\circ}(\mathrm{VETADO})$

$\S 2^{\circ} \mathrm{O}$ relator, considerando a relevância da matéria e a representatividade dos postulantes, poderá, por despacho irrecorrível, admitir, observado o prazo fixado no parágrafo anterior, a manifestação de outros órgãos ou entidades. $[\ldots]$

Art. 9o Vencidos os prazos do artigo anterior, o relator lançará o relatório, com cópia a todos os Ministros, e pedirá dia para julgamento.

§ 1 Em caso de necessidade de esclarecimento de matéria ou circunstância de fato ou de notória insuficiência das informações existentes nos autos, poderá o relator requisitar informações adicionais, designar perito ou comissão de peritos para que emita parecer sobre a questão, ou fixar data para, em audiência pública, ouvir depoimentos de pessoas com experiência e autoridade na matéria.

$\S 2$ - O relator poderá, ainda, solicitar informações aos Tribunais Superiores, aos Tribunais federais e aos Tribunais estaduais acerca da aplicação da norma impugnada no âmbito de sua jurisdição.

§ 3- As informações, perícias e audiências a que se referem os parágrafos anteriores serão realizadas no prazo de trinta dias, contado da solicitação do relator" (BRASIL, 1999b). 
dezembro de $1999^{3}$.

Ademais, amici curiae apresentaram argumentos no julgamento sobre o Código Florestal (Lei 12.651/2012) perante o Supremo Tribunal Federal, apoiando as ações, bem como outras entidades defenderam a improcedência da ação, tornando o debate aberto e plural na defesa e proteção ao meio ambiente. (BRASIL, 2017).

Essa percepção do tema ficou demonstrada que a figura do amicus curiae configura-se em um grande instrumento que norteia a participação social para o debate, a proteção e a defesa ambiental no Supremo Tribunal Federal, no controle concentrado de constitucionalidade. Cumpre ter presente, desde logo, que se mostra plenamente legítima, com o novo diploma processual civil, artigo 138, a intervenção do instituto nos demais processos, desde que haja relevância da matéria, a especificidade do tema objeto da demanda ou a repercussão social da controvérsia, o que se aplica, pode-se dizer, em todas as matérias ambientais:

Art. 138. O juiz ou o relator, considerando a relevância da matéria, a especificidade do tema objeto da demanda ou a repercussão social da controvérsia, poderá, por decisão irrecorrível, de ofício ou a requerimento das partes ou de quem pretenda manifestar-se, solicitar ou admitir a participação de pessoa natural ou jurídica, órgão ou entidade especializada, com representatividade adequada, no prazo de 15 (quinze) dias de sua intimação (BRASIL, 2015).

Sendo assim, diante das razões expostas, e considerando, sobretudo, os fundamentos que lhe dão suporte, e que levam a concluir, em face da importância da relação Estado e sociedade para resguardar o direito ambiental, ergue-se o instituto do amicus curiae como interessado em contribuir para a causa.

Não se desconhece que há uma pluralidade no debate sobre a matéria ambiental, a fim de obter uma satisfação maior do que a das próprias partes do processo, buscando a uniformização de um direito coletivo social, que prima pela participação social, e atua, dessa forma, como aliado na defesa e proteção ao direito ao meio ambiente.

\section{CONSIDERAÇÕES FINAIS}

Presente esse contexto, e diante da necessidade de proteção ambiental na sociedade hodierna, mostra-se imperioso reconhecer, consoante acentua a norma constitucional brasileira (artigo 225), o pressuposto de que a proteção ao meio ambiente não constitui tarefa restrita ao âmbito do Poder Público, mas de todos os atores sociais, em sentido lato sensu. Nesse ponto, vê-se abandonada, pois, a concepção de uma democracia meramente representativa para se adotar uma soberania de acepção mais direta, em que a sociedade vem a interferir diretamente nas questões que envolvam seus interesses, bem como o interesse coletivo, no caso, o meio ambiente. Além do mais, a participação é que propicia que a decisão tomada, nesses casos, seja cada vez mais condizente com os anseios da comunidade.

Assim, é necessário que se reconheça instrumentos que permitam a participação direta da sociedade são necessários para a proteção do meio ambiente e, aqui, além daqueles mencionados no âmbito dos três Poderes Estatais, neste ponto, assume inquestionável relevo a utilização do

3 “Art. 6ํㅡㄹ Apreciado o pedido de liminar, o relator solicitará as informações às autoridades responsáveis pela prática do ato questionado, no prazo de dez dias.

$\S 1^{\circ}$ Se entender necessário, poderá o relator ouvir as partes nos processos que ensejaram a argüição, requisitar informações adicionais, designar perito ou comissão de peritos para que emita parecer sobre a questão, ou ainda, fixar data para declarações, em audiência pública, de pessoas com experiência e autoridade na matéria.

$\S 2$ o Poderão ser autorizadas, a critério do relator, sustentação oral e juntada de memoriais, por requerimento dos interessados no processo" (BRASIL, 1999b). 
instituto amicus curiae, compreendido como forma de participação social pertencente ao Estado Julgador, que se configura em um instrumento que pluraliza e democratiza o processo. Sendo que o controle jurisdicional à proteção ao meio ambiente, como resposta social, como instrumento de afetividade de normas sociais ou como instrumento de prevenção, será sempre a última trincheira da cidadania.

Observa-se, dessa forma, o significado e a importância do amicus curiae a possibilitar a participação social nos processos que envolvem o direito ao meio ambiente, de interesse ínsito social, propicia que a sociedade, a primeira e a última a ser afetada pela questão ambiental, possa participar na defesa e na proteção ao meio ambiente em demandas judiciais - que antes não poderia participar, pois, não era parte, mas, por vezes, diretamente afetada pela decisão. É por essa razão que o instituto, contribuirá, em tal contexto, incontornável dever jurídico do Estado e constituirá, por isso mesmo, resposta legítima do Poder Público à frente de todas as complicações e problemas que se sentenciam a entraves e inibições, no campo do meio ambiente, o que se expõe de maneira despretensiosa nesse artigo para que se utilize no aprimoramento e edificação de um espaço sustentável, ante a lei universal de causa e efeito.

\section{REFERÊNCIAS}

AGUIAR, Mirella de Carvalho. Amicus curiae. Salvador: JusPODIVM, 2005.

AMADO, Frederico. Direito ambiental. Salvador: Juspodium, 2017.

BIANCHI, Patricia Nunes Lima; FERREIRA, Heline Sivini. Os instrumentos jurisdicionais ambientais na constituição brasileira. In: CANOTILHO, José Joaquim Gomes; LEITE, José Rubens Morato (org.). Direito constitucional ambiental brasileiro. 2 ed. São Paulo: Saraiva, 2008.

BOFF, Leonardo. Ecologia: grito da terra, grito dos pobres. Rio de Janeiro: Vozes, 2015.

BRASIL. [Constituição (1988)]. Constituição da República Federativa do Brasil. Brasília, DF: Presidência da República, 1988. Disponível em: http://www.planalto.gov.br/ccivil_03/ constituicao/constituicao.htm. Acesso em: 14 mar. 2019.

BRASIL. Lei 13.105, de 16 de março de 2015. Código de Processo Civil. Brasília, DF: Presidência da República, 2015. Disponível em: http://www.planalto.gov.br/ccivil_03/_ato20152018/2015/lei/113105.htm. Acesso em: 16 ago. 2019.

BRASIL. Lei 9.868, de 10 de novembro de 1999. Dispõe sobre o processo e julgamento da Ação Direta de Inconstitucionalidade e da Ação Declaratória de Constitucionalidade perante o Supremo Tribunal Federal. Brasília, DF: Presidência da República, 11 nov. 1999a. Disponível em: http://www.planalto.gov.br/ccivil_03/Leis/L9868.htm. Acesso em: 15 mar. 2019.

BRASIL. Lei 9.882, de 3 de dezembro de 1999. Dispõe sobre o processo e julgamento da Arguição de Descumprimento de Preceito Fundamental, nos termos do $\S 1^{\circ}$ do art. 102 da Constituição Federal. Brasília, DF: Brasília, DF: Presidência da República. 1999b. Disponível em: http://www.planalto.gov.br/ccivil_03/Leis/L9882.htm. Acesso em: 15 mar. 2019.

BRASIL. Supremo Tribunal Federal. Ação Direta de Inconstitucionalidade 3540/DF. Tratase de ação direta que, ajuizada pelo eminente Senhor Procurador-Geral da República, objetiva 
o reconhecimento da inconstitucionalidade do artigo $1^{\circ}$ da Medida Provisória $n^{\circ} 2.166--67$, de 24/08/2001, na parte em que alterou o art. $4^{\circ}$, "caput" e $\S \S 1^{\circ}, 2^{\circ}, 3^{\circ}, 4^{\circ}, 5^{\circ}, 6^{\circ}$ e $7^{\circ}$, da Lei $n^{\circ}$ 4.771, de 15/09/1965, que instituiu o antigo Código Florestal. Cabe-me observar, no entanto, que sobreveio ao ajuizamento da presente ação direta a edição da Lei ${ }^{\circ}{ }^{0} 12.651$, de 25/05/2012, que expressamente revogou os diplomas normativos ora questionados neste processo objetivo de controle abstrato de constitucionalidade, como claramente resulta do seu artigo 83, que assim dispõe [...]. Requerente: Procurador-Geral da República. Requerido: Presidente da República. Relator: Min. Celso de Mello, 1 de setembro de 2005. Disponível em: http://www.stf.jus.br. Acesso em: 13 jul. 2019.

BRASIL. Supremo Tribunal Federal. Ação Direta de Inconstitucionalidade 3378/DF. AÇÃO DIRETA DE INCONSTITUCIONALIDADE. ART. 36 E SEUS $\S \S 1^{\circ}, 2^{\circ}$

E $3^{\circ}$ DA LEI No 9.985, DE 18 DE JULHO DE 2000. CONSTITUCIONALIDADE DA COMPENSAÇÃO DEVIDA PELA IMPLANTAÇÃO DE EMPREENDIMENTOS DE SIGNIFICATIVO IMPACTO AMBIENTAL. INCONSTITUCIONALIDADE PARCIAL DO $\S 1^{\circ}$ DO ART. 36. 1. O compartilhamento-compensação ambiental de que trata o art. 36 daLei $\mathrm{n}^{\circ} 9.985 / 2000$ não ofende o princípio da legalidade, dado haver sido a própria lei que previu o modo de financiamento dos gastos com as unidades de conservação da natureza. De igual forma, não há violação ao princípio da separação dos Poderes, por não se tratar de delegação do Poder Legislativo para o Executivo impor deveres aos administrados [...]. Requerente: Confederação Nacional da Indústria - CNI. Requerido: Presidente da República. Relator: Min. Carlos Britto, 9 de abril de 2008. Disponível em: http://www.stf.jus.br. Acesso em: 13 jul. 2019.

BRASIL. Supremo Tribunal Federal. Arguição de Descumprimento de Preceito Fundamental 101/DF. ARGÜIÇÃO DE DESCUMPRIMENTO DE PRECEITO FUNDAMENTAL: ADEQUAÇÃO. OBSERVÂNCIA DO PRINCÍPIO DA SUBSIDIARIEDADE. ARTS. 170, 196 E 225 DA CONSTITUIÇÃO DA REPÚBLICA. CONSTITUCIONALIDADE DE ATOS NORMATIVOS PROIBITIVOS DA IMPORTAÇÃO DE PNEUS USADOS. RECICLAGEM DE PNEUS USADOS: [...]. Requerente: Presidente da República. Relatora: Min. Cármen Lúcia, 11 DE março de 2009. Disponível em: http://www.stf.jus.br/. Acesso em: 13 juL. 2019.

CARVALHO, Délton Winter de. Dano ambiental futuro: a responsabilização civil pelo risco ambiental. Rio de Janeiro: Forense, 2008.

DEL PRÁ, Carlos Gustavo Rodrigues. Amicus curiae: instrumento de participação democrática e de aperfeiçoamento da prestação jurisdicional. Curitiba: Juruá, 2007.

FURRIELA, Rachel Biderman. Democracia, cidadania e proteção do meio ambiente. São Paulo: Annablume: Fapesp, 2002.

GAIO, Daniel. A interpretação do direito de propriedade em face da proteção constitucional do meio ambiente urbano. Rio de Janeiro: Renovar, 2015.

LEAL, Mônia Clarissa Hennig; MAAS, Rosana Helena. O Amicus curiae e o Supremo

Tribunal Federal: fundamentos teóricos e análise crítica. Curitiba: Multideia, 2014.

LEAL, Rogério Gesta. Ordem econômica e meio ambiente no Brasil: elementos teóricos e 
fundamentais à solução de casos judiciais concretos. In: BRAVO, A. S. Justicia y médio ambiente (org.). Espanha: Punto rojo libros, 2013.

LEITE, José Rubens Morato. Dano ambiental: do individual ao coletivo extrapatrimonial. 2. ed. rev., atual. ampl. São Paulo: Editora Revista dos Tribunais, 2003.

LEITE, José Rubens Morato. Sociedade de risco e estado. In: CANOTILHO, José Joaquim Gomes; LEITE, José Rubens Morato (org.). Direito constitucional ambiental brasileiro. 2 ed. rev. São Paulo: Saraiva, 2008.

MACHADO, Paulo Affonso Leme. Direito Ambiental Brasileiro. São Paulo: Malheiros, 2016.

RIO DE JANEIRO. Declaração do Rio sobre meio ambiente e desenvolvimento. Rio de Janeiro, 1992. Disponível em: http://www.meioambiente.pr.gov.br/arquivos/File/agenda21/ Declaracao_Rio_Meio_Ambiente_Desenvolvimento.pdf. Acesso em: 16 ago. 2019.

SANTANA, Viviane Nobre. A participação do amicus curiae nas decisões judiciais e sua consequente contribuição para efetivação de políticas públicas. Revista Brasileira de Políticas Públicas, Brasília, DF, v. 9, n. 1, p. 428-448, abr. 2019.

SANTOS, Esther Maria Brighenti dos. Amicus curiae: um instrumento de aperfeiçoamento nos processos de controle de constitucionalidade. Revista Jus Navigandi, Teresina, ano 10, n. 906, 26 dez. 2005. Disponível em: https://jus.com.br/artigos/7739. Acesso em: 10 mar. 2019.

SARLET, Ingo Wolfgang; FENSTERSEIFER, Tiago. Princípios do direito ambiental. 2 ed. São Paulo: Saraiva, 2017.

SIRVINSKAS, Luis Paulo. Manual de direito ambiental. 16. ed. São Paulo: Saraiva Educação, 2018.

SOUZA, José Franklin de. Intervenção de terceiros e coisa julgada. Leme: J. H. Mizuno, 2007.

BRASIL. Supremo Tribunal Federal. Representantes de "amigos da Corte" apresentam argumentos em julgamento sobre Código Florestal. Brasília: STF, 2017. Disponível em: http:// www.stf.jus.br/portal/cms/verNoticiaDetalhe.asp?idConteudo=355716.Acesso em: 18 ago. 2019.

TRENNEPOHL, Terence Dornelles. Fundamentos de direito ambiental. Salvador: Podivm, 2007.

Como citar: CASTRO, Flavio Barboza; LEAL, Rogério Gesta. Amicus Curiae: um aliado na defesa e proteção ao meio ambiente. Revista do Direito Público, Londrina, v. 16, n. 1, p. 119-132, abr. 2021. DOI: 10.5433/24157-108104-1.2021v16n1p. 119. ISSN: 1980-511X

Recebido em: 02/09/2019

Aprovado em: 26/07/2020 